\title{
Ataxia-photosensitivity-short stature syndrome
}

INSERM

\section{Source}

INSERM. (1999). Orphanet: an online rare disease and orphan drug data base. Ataxiaphotosensitivity-short stature syndrome. ORPHA:1184

Ataxia-photosensitivity-short stature syndrome is a rare, genetic, multiple congenital anomalies/dysmorphic syndrome characterized by cerebellar-like ataxia, photosensitivity (mainly of the face and trunk), short stature and intellectual disability. Additonal features include clinodactyly, single palmar transverse crease, high-arched palate, pseudohypertrophy of the calves and aortic valve lesions. There have been no further descriptions in the literature since 1983. 